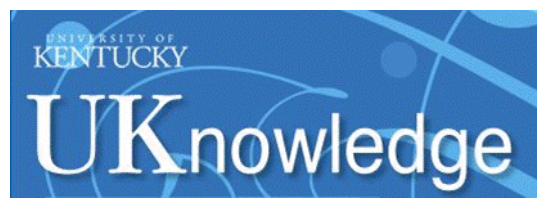

University of Kentucky

UKnowledge

Epidemiology and Environmental Health Faculty Publications

Epidemiology and Environmental Health

2013

\title{
Task-Based Noise Exposures for Farmers Involved in Grain Production
}

\author{
Michael J. Humann \\ University of lowa \\ Wayne T. Sanderson \\ University of Kentucky, wayne.sanderson@uky.edu \\ Kelley J. Donham \\ University of lowa \\ Kevin M. Kelly \\ University of lowa
}

Follow this and additional works at: https://uknowledge.uky.edu/epidemiology_facpub

Part of the Epidemiology Commons

Right click to open a feedback form in a new tab to let us know how this document benefits you.

\section{Repository Citation}

Humann, Michael J.; Sanderson, Wayne T.; Donham, Kelley J.; and Kelly, Kevin M., "Task-Based Noise Exposures for Farmers Involved in Grain Production" (2013). Epidemiology and Environmental Health Faculty Publications. 5.

https://uknowledge.uky.edu/epidemiology_facpub/5

This Article is brought to you for free and open access by the Epidemiology and Environmental Health at UKnowledge. It has been accepted for inclusion in Epidemiology and Environmental Health Faculty Publications by an authorized administrator of UKnowledge. For more information, please contact UKnowledge@lsv.uky.edu. 


\section{Task-Based Noise Exposures for Farmers Involved in Grain Production}

Digital Object Identifier (DOI)

http://dx.doi.org/10.13031/jash.19.9540

\section{Notes/Citation Information}

Published in Journal of Agricultural Safety and Health, v. 19, no. 2, p. 101-113.

Copyright 2013 American Society of Agricultural and Biological Engineers

The copyright holder has granted permission for posting the article here. 


\title{
Task-Based Noise Exposures for Farmers Involved in Grain Production
}

\author{
M. J. Humann, W. T. Sanderson, K. J. Donham, K. M. Kelly
}

ABstract. Few studies have been done examining noise exposures associated with agricultural tasks. This study was conducted to address that research gap by calculating the noise exposures for tasks and equipment associated with grain production and assessing the variability in those exposures. An additional aim of this study was to identify tasks and equipment that could be targeted for intervention strategies as a means toward reducing the total noise exposures of farmers and farm workers. Through the use of personal noise dosimetry and direct observation, over 30,000 one-minute noise exposure measurements and corresponding task and equipment data were collected on 18 farms and compiled into a task-based noise exposure database. Mean noise exposures were calculated for 23 tasks and 18 pieces of equipment. The noise exposures for the tasks and equipment ranged from 78.6 to $99.9 \mathrm{dBA}$ and from 80.8 to $96.2 \mathrm{dBA}$, respectively, with most of the noise exposures having a large standard deviation and maximum noise exposure level. Most of the variability in the task and equipment noise exposures was attributable to within-farm variations (e.g., work practices, distance from noise sources). Comparisons of the mean noise exposures for the agricultural tasks and equipment revealed that most were not statistically different. Grain production tasks and equipment with high mean noise exposures were identified. However, the substantial variability in the noise exposures and the occurrence of intense noise measurements for nearly every task and piece of equipment indicate that targeting a few specific tasks or equipment for intervention strategies would reduce lifetime noise exposure but would not completely eliminate exposure to hazardous noise levels.

Keywords. Noise, Noise exposure, Safety and health.

$\mathrm{T}$ Task-based noise exposure analysis may have the potential to identify tasks that expose farmers to hazardous noise levels and reduce the risk of noise-induced hearing loss by allowing interventions to be targeted toward those tasks. While allday monitoring to determine time-weighted average (TWA) exposures is useful, the changing work environment, variability in tasks and equipment, and varying workday hours limit the ability of the $8 \mathrm{~h}$ TWA to accurately characterize the exposures and associated health risks for agricultural workers, or to identify areas where noise exposures can be targeted for reduction.

Task-based exposure assessments have been conducted for numerous hazards in

Submitted for review in December 2011 as manuscript number JASH 9540; approved for publication by the Journal of Agricultural Safety and Health of ASABE in March 2013.

The authors are Michael J. Humann, PhD, Principal Investigator, Department of Occupational and Environmental Health, College of Public Health, The University of Iowa, Iowa City, Iowa; Wayne T. Sanderson, $\mathrm{PhD}$, Professor and Chair, Department of Epidemiology, College of Public Health, University of Kentucky, Lexington, Kentucky; Kelley J. Donham, MS, DVM, Professor, and Kevin M. Kelly, PhD, Research Scientist, Department of Occupational and Environmental Health, College of Public Health, The University of Iowa, Iowa City, Iowa. Corresponding author: Michael Humann, NIOSH, 1095 Willowdale Rd, MS 2800, Morgantown, WV 26505; phone: 304-285-6193; e-mail: humann.michael@gmail.com. 
addition to noise exposure (Verma et al., 2004; Warren et al., 2006; Reames et al., 2001; Eduard and Bakke, 1999). These assessments allow for the characterization of full-day exposure, while also permitting assessment of short-term hazards that might not be identified through a standard full-day exposure sampling protocol (Susi et al., 2000). Taking measurements at the task level has been shown to be a useful method for determining hazardous exposures in complex dynamic environments (Goldberg et al., 1997). Furthermore, epidemiologic studies benefit from task-based exposure assessments because they support the validity of cumulative exposure histories by limiting the misclassifications that can occur when reconstructing past exposures through employment records or work histories (Benke et al., 2000).

Assessment data on task-based noise exposures for agricultural operations are limited (Franklin et al., 2006; McBride et al., 2003; Depczynski et al., 2005; Humann et al., 2011; Milz et al., 2008; Lander et al., 2007). The few studies that have examined noise exposures of agricultural tasks used a variety of techniques for measuring and calculating task-based noise exposures. Each study also examined noise exposures for a varying number of tasks. Some studies reported a range of exposures, while others calculated mean exposure. Regardless of the methods, the noise exposures of many agricultural tasks examined in these studies exceeded $85 \mathrm{dBA}$ (A-weighted decibels), indicating a risk for developing noise-induced hearing loss. Furthermore, the noise exposures for the agricultural tasks in these studies were all highly variable.

The objective of this study was to calculate the mean noise exposures for farmers and farm workers at the task level by developing a large database of noise measurements and corresponding task information for farmers involved in grain production. A field study was conducted to: (1) measure and calculate the noise exposures for specific tasks conducted on grain production operations, and (2) characterize the variability in the taskbased mean noise exposures. The results of this study will provide useful information on the noise exposures associated with agricultural tasks and identify tasks with potentially hazardous noise levels that should be targeted for control.

\section{Materials and Methods}

\section{Study Population}

Noise exposure, task, and equipment data were collected from farmers and farm workers located in two counties in the southern Red River Valley region of Minnesota and North Dakota. According to the 2007 Census of Agriculture, the characteristics of farms in the two counties are similar (USDA, 2007a, 2007b). Cash crops accounted for $88 \%$ and $98 \%$ of all farm products sold, with most acres in production of soybeans, wheat, corn, and sugarbeets. In one county, there were 943 farms with a mean size of 961 acres. The other county had 428 farms with a mean size of 993 acres. The majority of farmers in both counties were male $(97 \%$ and $93 \%)$ with an average age of 54 years.

Farms where production was primarily grain crops were eligible for participation. Eligible farms were identified through County Extension and USDA Farm Services Agency (FSA) offices. A recruitment letter was sent to 30 randomly selected farms in each county with information about the study, notification about an upcoming recruitment telephone call, and a "Do Not Contact" return postcard, which allowed the recipient to opt out prior to the follow-up telephone call.

The random recruitment resulted in a response rate of $5 \%$, so a secondary non-random 
recruitment method was conducted. The principal investigator visited three farms where a prior personal relationship existed to discuss the project and inquire about participation. From there, a networking sampling method was carried out in order to put together a convenience sample of farms for the study. The principal investigator talked to friends and neighbors of these previously identified farms and utilized county-based contacts to identify additional farms. Eligible farms where the principal operator indicated a willingness to participate were then sent the standard recruitment letter, and recruitment was completed with a follow-up telephone call.

\section{Data Collection}

\section{Task and Equipment Data}

Direct observation of participants was used to collect task and equipment data corresponding to one-minute noise measurements. Using a task observational form, the field researcher was able to write a description of the tasks conducted by the participants and record within an accuracy of five minutes when the tasks were initiated and completed. The field researcher also recorded the start and stop times when equipment was used by participants or when they were working in close proximity to the equipment. The start and stop times were only recorded if the equipment was powered on or operational, regardless of the task being conducted. In addition to task and equipment information, the start and stop times of hearing protection use was recorded. A premonitoring questionnaire was also completed by participants prior to noise monitoring to collect demographic and farm information.

\section{Noise Exposure Data}

Noise exposure measurements were collected using NoisePro DL noise dosimeters (Quest Technologies, Oconomowoc, Wisc.) with NIOSH criteria (slow response, Aweighting, and three decibel exchange rate) (NIOSH, 1998). The dosimeters were programmed to calculate the average noise exposure every minute. Dosimeter thresholds were disabled, allowing measurement of noise for tasks where noise levels were consistently less than $80 \mathrm{~dB}$.

Noise exposure measurements were collected at each farm three times (spring, summer, and fall) during the growing season. This ensured that data collection occurred during a time of the year when a variety of grain production tasks were taking place. One or two individuals were monitored at each farm during sampling. Farms were randomly scheduled for noise monitoring during each round of data collection. Two criteria were used to determine if a farm was available for data collection: (1) whether the monitored individuals would be putting in a full work day (eight hours), and (2) whether the primary work tasks that day would be related to grain production.

On the day of noise exposure monitoring, the field researcher met with the principal operator and employees or family members working on the farm and selected one or two participants for monitoring. Two participants were selected only if they would both be working in the same general area. One was designated the primary and was observed continuously; the other was designated the secondary and was observed periodically during sampling. The participants were also given the pre-monitoring survey to complete.

To conduct the noise exposure monitoring, the participants were fitted with a calibrated noise dosimeter. Once the dosimeters were activated and sampling began, the participants resumed their normal work routine. The noise dosimeters were postcalibrated, and the data from the dosimeters were downloaded to a computer using 
Questsuite software at the conclusion of the sampling day.

\section{Data Analysis}

Data from the dosimeters, task observational forms, and pre-monitoring questionnaires were assembled into a master database. The one-minute noise exposure measurements and corresponding timestamps were exported into a Microsoft Excel spreadsheet and labeled with the farm identifier (FID), subject identifier (SID), and sample date. Demographic data from the pre-monitoring questionnaire were entered into an Epi Info database. Task and equipment data from the observational form were entered into an Access dataset with corresponding timestamps, FIDs, SIDs, and sample dates. Task data from the observational form were categorized into specific task categories during data entry by assigning the written task descriptions to a specific task category. Using the FID, SID, dates, and timestamps, data from the two datasets were merged into a final SAS dataset. The final database contained all one-minute noise measurements linked with the corresponding task, equipment, and demographic data. To ensure that the stop time for one task or piece of equipment did not overlap with the start time for the next, stop times for all tasks and equipment were moved one minute earlier. All data analyses were performed with SAS (version 9.2, SAS Institute, Inc., Cary, N.C.).

Task and equipment noise exposures $\left(L_{\text {task }}\right)$ were determined by taking the one-minute noise measurements corresponding to a specific task or piece of equipment, farm, participant, and date, and calculating the mean noise exposures using equation 1 (Berger et al., 2003):

$$
L_{\text {task }}=q \log 10\left[\left(\frac{1}{T}\right) \times \sum_{i=1}^{N}\left(t_{i} \times 10^{\left(\frac{L_{i}}{q}\right)}\right)\right]
$$

where

$L_{i}=$ one-minute noise measurements

$t_{i}=$ duration of $L_{i}$ exposure

$T=$ duration of total sample time for a specific task

$q=$ exchange rate $/ \log 2$.

Using the Proc Mixed procedure in SAS, an unconditional random effects model was used to calculate the within-farm and between-farm variance components for the mean task and equipment noise exposures. This type of linear regression model did not contain additional covariates and was used to determine the variability of the noise exposures within an individual farm and between all the farms. Additionally, a Tukey-Kramer multiple comparison procedure was conducted separately for the mean task noise exposures and equipment noise exposures to identify means that were significantly different $(\mathrm{p}<0.05)$ from each other.

\section{Results}

\section{Demographic Characteristics}

Overall, 35 farmers or farm workers from 18 farms participated in the study. Only three farms were recruited as a result of the random recruitment process; the remaining 
Table 1. Demographic characteristics of study participants $(N=32) .^{[a]}$

\begin{tabular}{|c|c|c|c|c|c|}
\hline \multicolumn{2}{|l|}{ Characteristics } & $\begin{array}{l}\text { Mean (SD) or } \\
\text { Frequency }^{[\mathrm{b}]}\end{array}$ & Median & Min. & Max. \\
\hline \multicolumn{2}{|l|}{$\begin{array}{l}\text { Age } \\
\end{array}$} & $42.7(14.3)$ & 44.0 & 16 & 71 \\
\hline \multicolumn{2}{|c|}{ Years farming } & $24.1(13.6)$ & 23.5 & 3 & 55 \\
\hline \multicolumn{2}{|c|}{ Hours worked per week (growing season) } & $58.1(17.7)$ & 60.0 & 8 & 100 \\
\hline \multicolumn{2}{|c|}{ Hours worked per week (off season) } & $26.7(13.6)$ & 30 & 0 & 50 \\
\hline \multicolumn{2}{|c|}{ Medically diagnosed hearing loss } & $6(18.7 \%)$ & & & \\
\hline \multicolumn{2}{|c|}{ Primary occupation farming } & $31(96.9 \%)$ & & & \\
\hline \multicolumn{2}{|c|}{ Participants with second job } & $8(25 \%)$ & & & \\
\hline \multirow[t]{2}{*}{ Gender } & Male & $31(96.9 \%)$ & & & \\
\hline & Female & $1(3.1 \%)$ & & & \\
\hline \multirow[t]{4}{*}{ Education } & Some high school & $3(9.4 \%)$ & & & \\
\hline & High school graduate & $8(25.0 \%)$ & & & \\
\hline & Some college & $7(21.9 \%)$ & & & \\
\hline & College graduate & $14(43.7 \%)$ & & & \\
\hline \multirow[t]{4}{*}{ Marital status } & Single & $7(21.9 \%)$ & & & \\
\hline & Married & $22(68.7 \%)$ & & & \\
\hline & Divorced & $2(6.3 \%)$ & & & \\
\hline & Widowed & $1(3.1 \%)$ & & & \\
\hline \multirow[t]{4}{*}{ Income } & Less than $\$ 40,000$ & $9(28.1 \%)$ & & & \\
\hline & $\$ 40,000$ to $\$ 80,000$ & $10(31.3 \%)$ & & & \\
\hline & More than $\$ 80,000$ & $8(25.0 \%)$ & & & \\
\hline & Refused to answer & $5(15.6 \%)$ & & & \\
\hline \multirow{4}{*}{$\begin{array}{l}\text { Often work around } \\
\text { loud noises }\end{array}$} & Never & $0(0 \%)$ & & & \\
\hline & Some of the time & $21(65.6 \%)$ & & & \\
\hline & Most of the time & $10(31.3 \%)$ & & & \\
\hline & All of the time & $1(3.1 \%)$ & & & \\
\hline \multirow[t]{4}{*}{ Hearing protection } & Never & $19(59.4 \%)$ & & & \\
\hline & Some of the time & $9(28.1 \%)$ & & & \\
\hline & Most of the time & $3(9.4 \%)$ & & & \\
\hline & All of the time & $1(3.1 \%)$ & & & \\
\hline
\end{tabular}

15 were recruited using the non-random recruitment method. The participants provided 79 daily noise samples, corresponding to 30,580 minutes of noise exposure data and noise exposures measurements for 588 individual task events.

Demographic characteristics of the study participants are presented in table 1. All but one of the participants was male. On average, participants were 43 years of age and had been farming for 24 years. All but one participant considered farming their primary occupation, and during the growing season participants worked an average of 58.1 hours per week. All participants reported working around loud noises, and nearly $60 \%$ reported never using hearing protection. However, only six participants $(19 \%)$ reported ever being told by a doctor or other healthcare professional that they had hearing loss.

The average farm size was 2357 acres. There were on average 2.8 family members and 2.2 hired employees per farm. Eighty-three percent of farms grossed over $\$ 100,000$ per year, and over half had farm assets valued over $\$ 1,000,000$. Remaining farm characteristics are given in table 2. From the task observational form, the percent time hearing protection was used by participants was calculated. Among all 30,580 one-minute noise measurements, hearing protection was used by participants only $3.8 \%$ of the time. 
Table 2. Characteristics of participating farms $(N=18)$.

\begin{tabular}{|c|c|c|c|c|c|}
\hline \multicolumn{2}{|c|}{ Characteristics } & $\begin{array}{l}\text { Mean (SD) or } \\
\text { Frequency }^{[\mathrm{a}]}\end{array}$ & Median & Min. & Max. \\
\hline \multicolumn{2}{|c|}{ Number of workers (family) } & $2.8(1.6)$ & 3 & 0 & 6 \\
\hline \multicolumn{2}{|c|}{ Number of workers (hired) } & $2.2(3.9)$ & 1 & 0 & 12 \\
\hline \multicolumn{2}{|c|}{ Number of tractors } & $5.6(1.4)$ & 6 & 3 & 8 \\
\hline \multicolumn{2}{|l|}{ Number of combines } & $1.6(0.5)$ & 2 & 1 & 2 \\
\hline \multicolumn{2}{|c|}{ Number of portable augers } & $3.2(1.0)$ & 3 & 2 & 6 \\
\hline \multicolumn{2}{|c|}{ Number of skid steers } & $0.8(0.4)$ & 1 & 0 & 2 \\
\hline \multicolumn{2}{|l|}{ Number of grain bins } & $10.7(6.1)$ & 10 & 0 & 24 \\
\hline \multicolumn{2}{|l|}{ Number of grain dryers } & $0.5(0.5)$ & 1 & 0 & 1 \\
\hline \multicolumn{2}{|l|}{ Number of grain trucks } & $3.3(1.8)$ & 3 & 0 & 8 \\
\hline \multicolumn{2}{|l|}{ Number of semis } & $1.8(1.4)$ & 2 & 0 & 5 \\
\hline \multicolumn{2}{|l|}{ Size of farm (acres) } & $2357(1286)$ & 2250 & 800 & 5400 \\
\hline \multirow[t]{4}{*}{ 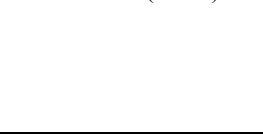 } & $<1200$ & $4(22.2 \%)$ & & & \\
\hline & 1200 to 2199 & $4(22.2 \%)$ & & & \\
\hline & 2200 to 3199 & $5(27.8 \%)$ & & & \\
\hline & $>3200$ & $5(27.8 \%)$ & & & \\
\hline \multirow[t]{2}{*}{ Farm production } & Grain and livestock & $2(11.1 \%)$ & & & \\
\hline & Grain only & $16(88.9 \%)$ & & & \\
\hline \multirow[t]{2}{*}{ Gross farm income } & Refused to answer & $2(16.7 \%)$ & & & \\
\hline & Over $\$ 100,000$ & $15(83.3 \%)$ & & & \\
\hline \multirow[t]{4}{*}{ Value of farm assets } & Refused to answer & $3(16.7 \%)$ & & & \\
\hline & Under $\$ 1,000,000$ & $3(16.7 \%)$ & & & \\
\hline & $\$ 1,000,000$ to $\$ 5,000,000$ & $8(44.4 \%)$ & & & \\
\hline & Over $\$ 5,000,000$ & $4(22.2 \%)$ & & & \\
\hline
\end{tabular}

\section{Task-Based Noise Exposures}

The mean noise exposures and summary statistics for the 23 task categories are listed in table 3. The noise exposures ranged from 78.6 to $99.9 \mathrm{dBA}$ for all tasks. Tasks with noise exposures greater than $85 \mathrm{dBA}$ were operating a grain vacuum ( $99.9 \mathrm{dBA})$, operating other equipment (94.1 dBA), unloading and loading grain bins (90.3 dBA), changing tires on vehicles and implements $(89.8 \mathrm{dBA})$, working around grain bins ( 86.3 $\mathrm{dBA})$, unloading grain at the elevator $(86.0 \mathrm{dBA})$, driving a grain truck $(85.9 \mathrm{dBA})$, and operating an all-terrain vehicle (ATV) (85.7 dBA). Only miscellaneous work around the farm (78.6 dBA), which included a wide variety of activities, had a noise exposure less than $80.0 \mathrm{dBA}$.

The standard deviations of the task-based mean noise exposures were large, in the context that a three-decibel increase or decrease in the noise level is a doubling or halving of the exposure's intensity (NIOSH, 1998). Only driving a grain truck; plowing, digging, and ditching fields; and operating a tractor during other field work had standard deviations less than 3.0 dBA. The within-farm variance accounted for most of the variability in the task-based noise exposures. The within-farm variance is attributed to the variability in the measurements of noise exposures at a specific farm, whereas the between-farm variance is attributed to the variability in the measurements from one farm to another. There was greater between-farm variance in the mean noise exposures for operating a grain vacuum; operating an ATV; operating a grain cart; plowing, digging, and ditching fields; and operating a tractor during other field work. In addition, except for operating a tractor during other field work, each of the tasks had at least one measurement (maximum dBA) greater than $85 \mathrm{dBA}$. 
Table 3. Noise exposure characteristics of common grain production tasks.

\begin{tabular}{|c|c|c|c|c|c|c|c|c|c|}
\hline \multirow[b]{2}{*}{ Grain Production Task } & \multicolumn{6}{|c|}{ Mean } & \multicolumn{3}{|c|}{ Variability in Measurement } \\
\hline & $\begin{array}{c}\text { No. } \\
\text { of } \\
\text { Days }^{[\mathrm{a}]}\end{array}$ & $\begin{array}{c}\text { No. } \\
\text { of } \\
\text { Farms }^{[\mathrm{b}]}\end{array}$ & $\begin{array}{c}\text { Sample } \\
\text { Time } \\
\text { (min) }\end{array}$ & $\begin{array}{l}\text { Mean } \\
(\mathrm{dBA})\end{array}$ & $\begin{array}{l}\text { Min. } \\
(\mathrm{dBA})\end{array}$ & $\begin{array}{l}\text { Max. } \\
(\mathrm{dBA})\end{array}$ & $\begin{array}{c}\mathrm{SD} \\
(\mathrm{dBA})\end{array}$ & $\begin{array}{c}\text { Within } \\
\text { Farm } \\
\text { Variance }\end{array}$ & $\begin{array}{c}\text { Between } \\
\text { Farm } \\
\text { Variance }\end{array}$ \\
\hline Operating grain vacuum & 4 & 4 & 140 & 99.9 & 96.8 & 102.8 & 3.0 & 0.9 & 7.9 \\
\hline Operating other equipment & 1 & 1 & 125 & 94.1 & - & - & - & - & - \\
\hline Unloading/loading grain bins & 11 & 7 & 40 & 90.3 & 85.1 & 94.1 & 3.2 & 10.2 & 0 \\
\hline $\begin{array}{l}\text { Changing tires on vehicles } \\
\text { and implements }\end{array}$ & 4 & 2 & 44 & 89.8 & 81.9 & 93.7 & 5.4 & 29.6 & 0 \\
\hline Working around grain bins & 11 & 7 & 21 & 86.3 & 79.0 & 91.3 & 3.7 & 13.9 & 0 \\
\hline Unloading grain at elevator & 12 & 9 & 25 & 86.0 & 82.1 & 95.4 & 3.6 & 10.5 & 2.8 \\
\hline Driving grain truck & 29 & 15 & 73 & 85.9 & 78.9 & 90.3 & 2.7 & 4.4 & 2.5 \\
\hline Operating ATV & 2 & 2 & 21 & 85.7 & 83.2 & 88.3 & 3.6 & 0.9 & 12.2 \\
\hline $\begin{array}{l}\text { Checking equipment/field/ } \\
\text { crops during field work }\end{array}$ & 30 & 17 & 17 & 84.0 & 72.7 & 94.3 & 4.7 & 15.7 & 7.2 \\
\hline Planting grain crops & 13 & 12 & 202 & 83.7 & 76.5 & 89.4 & 3.6 & 13.2 & $<0.1$ \\
\hline Prepping equipment & 56 & 18 & 32 & 83.6 & 73.7 & 90.6 & 3.7 & 13.9 & 0 \\
\hline Operating grain cart & 8 & 6 & 93 & 83.3 & 75.3 & 93.7 & 5.8 & 2.5 & 30.7 \\
\hline Combining grain crops & 25 & 14 & 202 & 83.2 & 77.3 & 92.2 & 3.6 & 6.8 & 6.4 \\
\hline Maintenance on equipment & 30 & 15 & 81 & 83.0 & 77.1 & 94.9 & 5.0 & 17.0 & 7.7 \\
\hline Spraying fields & 8 & 5 & 161 & 82.8 & 77.9 & 88.1 & 3.4 & 11.3 & 0 \\
\hline $\begin{array}{l}\text { Plowing/digging/ditching } \\
\text { fields }\end{array}$ & 14 & 9 & 142 & 82.6 & 77.8 & 87.9 & 2.5 & 2.5 & 4.5 \\
\hline Misc. work in fields & 19 & 12 & 36 & 82.6 & 72.8 & 91.9 & 4.9 & 20.1 & 4.3 \\
\hline $\begin{array}{l}\text { Driving tractor for non-field } \\
\text { work }\end{array}$ & 33 & 17 & 27 & 82.1 & 74.4 & 89.1 & 3.8 & 11.5 & 3.3 \\
\hline Working in shop & 29 & 13 & 42 & 81.9 & 72.6 & 97.3 & 6.0 & 35.7 & 0 \\
\hline $\begin{array}{l}\text { Driving pickup or personal } \\
\text { vehicle }\end{array}$ & 29 & 15 & 38 & 81.7 & 73.9 & 89.7 & 3.9 & 12.8 & 2.2 \\
\hline $\begin{array}{l}\text { Operating tractor during } \\
\text { other field work }\end{array}$ & 6 & 4 & 178 & 81.5 & 77.8 & 84.9 & 2.5 & 0.1 & 9.3 \\
\hline Unaccounted for work time & 28 & 12 & 55 & 80.2 & 70.0 & 91.2 & 4.8 & 23.3 & 0 \\
\hline Misc. work around farm & 49 & 18 & 42 & 78.6 & 68.7 & 86.7 & 4.9 & 19.6 & 4.9 \\
\hline
\end{tabular}

[a] Number of days during noise monitoring when the task was observed.

[b] Number of farms during noise monitoring where the task was observed.

For the most part, the mean noise exposures were not statistically different between most of the tasks (data not shown). Operating a grain vacuum (mean $=99.9 \mathrm{dBA}, \mathrm{SD}=$ $3.0 \mathrm{dBA})$ and unloading grain at the elevator $($ mean $=86.0 \mathrm{dBA}, \mathrm{SD}=3.6 \mathrm{dBA})$ were the tasks with means greater than $85 \mathrm{dBA}$ that were significantly different from most of the remaining tasks. Similarly, for the tasks with means less than $85 \mathrm{dBA}$, miscellaneous work around the farm (mean $=78.6 \mathrm{dBA}, \mathrm{SD}=4.9$ ) was significantly different from most other tasks. Unaccounted for work time (mean $=80.2 \mathrm{dBA}, \mathrm{SD}=4.8$ ), although not a precise task, also had a mean noise exposure significantly different from several of the other tasks (unloading/loading grain bins, changing tires on vehicles and implements, unloading grain at elevator, and driving grain truck).

\section{Equipment Noise Exposures}

Table 4 presents the mean noise exposures for specific agricultural equipment used by or in close proximity to participants (only when powered on or operational) and does not corresponding to any specific task. Similar to the task noise exposures, exposure from the grain vacuum was the highest (96.2 dBA). Other equipment resulting in mean noise exposures greater than $85 \mathrm{dBA}$ included grain bin spreaders (93.6 dBA), grain dryers (91.4 dBA), grain augers (89.8 dBA), skid steers (89.2 dBA), 
Table 4. Noise exposure characteristics from common grain production equipment (only when powered on or operational).

\begin{tabular}{|c|c|c|c|c|c|c|c|c|c|}
\hline \multirow[b]{2}{*}{ Grain Production Equipment } & \multicolumn{6}{|c|}{ Mean } & \multicolumn{3}{|c|}{ Variability in Measurement } \\
\hline & $\begin{array}{c}\text { No. } \\
\text { of } \\
\text { Days }^{[\mathrm{a}]}\end{array}$ & $\begin{array}{c}\text { No. } \\
\text { of } \\
\text { Farms }^{[\mathrm{b}]}\end{array}$ & $\begin{array}{c}\text { Sample } \\
\text { Time } \\
\text { (min) }\end{array}$ & $\begin{array}{l}\text { Mean } \\
(\mathrm{dBA}) \\
\end{array}$ & $\begin{array}{l}\text { Min. } \\
(\mathrm{dBA})\end{array}$ & $\begin{array}{c}\text { Max. } \\
\text { (dBA) }\end{array}$ & $\begin{array}{c}\mathrm{SD} \\
(\mathrm{dBA})\end{array}$ & $\begin{array}{c}\text { Within } \\
\text { Farm } \\
\text { Variance }\end{array}$ & $\begin{array}{c}\text { Between } \\
\text { Farm } \\
\text { Variance }\end{array}$ \\
\hline Grain vacuums & 5 & 5 & 82 & 96.2 & 80.8 & 102.4 & 8.9 & 1.0 & 78.4 \\
\hline Grain bin spreader & 1 & 1 & 24 & 93.6 & - & - & - & - & - \\
\hline Grain dryers & 5 & 4 & 24 & 91.4 & 88.0 & 94.9 & 2.7 & 0.5 & 6.8 \\
\hline Grain augers & 14 & 10 & 23 & 89.8 & 84.8 & 96.8 & 3.8 & 14.2 & 0 \\
\hline Skid steers & 5 & 4 & 17 & 89.2 & 85.7 & 93.8 & 3.9 & 15.2 & 0 \\
\hline Air compressors & 11 & 10 & 19 & 89.1 & 79.8 & 102.2 & 6.1 & 1.5 & 39.8 \\
\hline Grain bin fans & 3 & 2 & 40 & 88.8 & 85.4 & 93.7 & 4.2 & 13.9 & 5.3 \\
\hline Power tools, continuous & 10 & 8 & 6 & 87.5 & 70.5 & 96.4 & 8.7 & 75.9 & 0 \\
\hline Grain trucks & 27 & 13 & 57 & 85.3 & 69.6 & 96.9 & 4.8 & 23.0 & 0 \\
\hline Power tools, intermittent & 8 & 6 & 36 & 84.5 & 68.9 & 94.6 & 8.6 & 1.6 & 87.2 \\
\hline Semis & 20 & 9 & 71 & 84.4 & 72.6 & 89.4 & 3.8 & 8.0 & 5.3 \\
\hline Power washers & 2 & 2 & 63 & 84.1 & 80.7 & 87.5 & 4.8 & 23.0 & 0 \\
\hline Non-power tools, intermittent & 8 & 7 & 85 & 83.8 & 73.5 & 97.1 & 7.8 & 60.3 & 0 \\
\hline Combines & 32 & 16 & 171 & 83.7 & 77.4 & 92.0 & 3.8 & 12.2 & 2.6 \\
\hline Tractors & 59 & 18 & 147 & 83.6 & 73.2 & 98.8 & 4.7 & 21.9 & 0 \\
\hline ATVs & 6 & 5 & 10 & 81.6 & 67.6 & 88.3 & 7.5 & 34.5 & 23.8 \\
\hline Pickup or personal vehicles & 32 & 15 & 36 & 81.1 & 72.7 & 88.4 & 4.0 & 11.3 & 5.3 \\
\hline Non-power tools, continuous & 11 & 9 & 33 & 80.8 & 70.2 & 91.0 & 5.3 & 6.9 & 21.1 \\
\hline
\end{tabular}

[a] Number of days during noise monitoring when the task was observed.

[b] Number of farms during noise monitoring where the task was observed.

air compressors $(89.1 \mathrm{dBA})$, fans on grain bins $(88.8 \mathrm{dBA})$, continuous use of power tools $(87.5 \mathrm{dBA})$, and grain trucks $(85.3 \mathrm{dBA})$. The noise exposures associated with specific equipment were more variable than the task noise exposures. Only the exposure from grain dryers had a standard deviation less than $3 \mathrm{dBA}$. For grain vacuums, grain dryers, air compressors, intermittent use of power tools, and continuous use of non-power tools, the variability between the farms was greatest, with the remaining equipment exposures demonstrating higher within-farm variability.

As with the task noise exposures, the mean noise exposures were not statistically different between most of the equipment (data not shown). Only the noise exposures for grain augers (mean $=89.8 \mathrm{dBA}, \mathrm{SD}=3.8 \mathrm{dBA})$, grain vacuums $($ mean $=96.2 \mathrm{dBA}, \mathrm{SD}=$ $8.9 \mathrm{dBA})$, and pickup or personal vehicles $($ mean $=81.1 \mathrm{dBA}, \mathrm{SD}=4.0 \mathrm{dBA}$ ) were significantly different from the noise exposures of four or more pieces of equipment.

\section{Discussion}

In this study, mean noise exposures for eight grain production tasks and nine pieces of equipment were found to be greater than $85 \mathrm{dBA}$ and could potentially lead to daily noise exposures greater than the NIOSH-recommended exposure limit (REL) (NIOSH, 1998). Controlling noise exposures when participating in these tasks or working with this equipment, through engineering controls or personal protective equipment, would reduce lifetime noise exposures and potentially decrease the prevalence of hearing loss among farmers and farm workers.

For example, given an eight-hour workday, if a farmer loaded grain bins for three hours, combined grain crops for four hours, and did miscellaneous work around the farm for one hour, with mean noise exposures for these tasks of 90.3, 83.2, and 78.6 dBA, respectively, this farmer would have a daily noise dose of $163 \%$ ( $87.1 \mathrm{dBA}, 8 \mathrm{~h}$ TWA $)$ 
based on the NIOSH REL (NIOSH, 1998). If the farmer, knowing that the mean noise exposure when loading grain bins was loud enough to cause hearing loss, wore hearing protection (e.g., ear muffs) that reduced the exposure to $80 \mathrm{dBA}$, then the daily noise dose would only be $48 \%$ ( $81.8 \mathrm{dBA}, 8 \mathrm{~h}$ TWA), thereby reducing the farmer's total daily noise exposure even if the noise exposure from the remaining tasks performed during the workday remained the same.

While the previous example shows that targeting intervention strategies to the highestexposure tasks and equipment will reduce lifetime noise exposure, this approach may not eliminate exposure to all hazardous noise levels. This is because of the large variability in the mean noise exposures (standard deviations ranging from 2.5 to $8.9 \mathrm{dBA}$ ). Furthermore, the mean noise exposures for almost all of the tasks and equipment had measurements loud enough (i.e., maximum dBA) to contribute to hearing loss in individuals exposed for sufficient durations (NIOSH, 1998). Combined with the long hours that farmers work (average $58 \mathrm{~h}$ per week), tasks and equipment with even moderate noise exposures could possibly lead to hearing loss.

This study is one of the few that calculated and examined task and equipment noise exposures of agricultural operations. Therefore, direct comparison of the results of this study with similar published work is limited. The ability to compare results to published literature is also difficult because prior studies used a variety of sampling methodologies. Further complicating comparisons, the convenience sample for this study resulted in larger farms participating, which were probably wealthier and had newer equipment, as opposed to smaller, more modest farms, which would have older, noisier equipment.

Two previous studies conducted comprehensive assessments of task and equipment noise exposures on farms in Australia (Franklin et al., 2006; Depczynski et al., 2005). Five of those exposure measurements were directly comparable to tasks and equipment in the current study. Mean noise levels of ATVs, augers, farm trucks, harvesters, and tractors with cabs were $86,93,85,83$, and $76 \mathrm{dBA}$, respectively. With the exception of tractors, these measurements were similar to the exposures for operating equipment in the current study. The mean noise level of operating tractors measured in the Australia study were closer to our exposures only when comparing the mean noise levels of older Australian tractors $(81.0 \mathrm{dBA})$ with the added effect of having the radio on in the cab. A key difference from the current study was that neither Depczynski et al. (2005) nor Franklin et al. (2006) measured personal noise exposures, but rather short-term noise levels measured near the farmers' ears.

Another task-based assessment of agricultural noise exposures was conducted as part of a study measuring noise exposures of farm families (Milz et al., 2008). Milz et al. (2008) measured and reported the range of noise exposures for five tasks and two pieces of equipment that were also examined in this study: power tools (75.5 to $82.3 \mathrm{dBA})$, tractors (75.8 to 78.3$)$, harvesting (78.4 to $88.0 \mathrm{dBA}$ ), planting (79.5 to $84.2 \mathrm{dBA}$ ), plowing ( 77.4 to $91.3 \mathrm{dBA}$ ), spraying fields ( 64.5 to $74.0 \mathrm{dBA}$ ), and maintenance (50.8 to $86.1 \mathrm{dBA}$ ). However, these results were standardized to an $8 \mathrm{~h}$ TWA, making comparisons difficult. The mean noise exposures measured in this study were greater than the ranges reported by Milz et al. (2008) for both continuous and intermittent power tools ( 87.5 and $84.5 \mathrm{dBA})$, tractors $(83.6 \mathrm{dBA})$, and spraying fields $(82.8 \mathrm{dBA})$ and within the range for combining grain crops $(83.2 \mathrm{dBA})$; planting grain crops $(83.7 \mathrm{dBA})$; plowing, digging, and ditching fields (82.6 dBA); and maintenance on equipment (83.0 dBA).

Two other studies also measured task-based noise exposures of agricultural operations 
(Humann et al., 2011; Lander et al., 2007). However, these studies focused on exposures specific to children and adolescents. Human et al. (2011) measured the task-based noise exposures for adolescents in agriculture, for which five tasks or equipment operations could be directly compared. Operating a tractor with a cab $(86.7 \mathrm{dBA})$ and working in a shop (83.2 dBA) had mean noise exposures greater than the exposures measured in the current study, while working around grain bins (85.5 dBA), riding ATVs ( $84.1 \mathrm{dBA})$, and using power tools $(81.9 \mathrm{dBA})$ had mean noise exposures less than the current study. Lander et al. (2007) found comparable results; operating power tools (89.0 dBA), skid steers $(88.0 \mathrm{dBA})$, and tractors with a cab $(84.0 \mathrm{dBA})$ were all within two decibels of the noise exposures measured in the current study.

Several methodological limitations may have affected the noise exposures in this study. This was a small study of only 35 farmers on 18 farms; therefore, few measurements were available for calculating the task and equipment noise exposures. A larger sample size would decrease the standard error of the means and better reflect the true noise exposures. The small sample size also reduced the ability to resolve mean differences across tasks and equipment. Characterization of the within-farm and betweenfarm variance components was also limited due to the small sample size and lack of repeated measurements across farms. For tasks and equipment with few repeated measures or small sample sizes, the variability components may be unreliable.

Tasks were also not selected for sampling in advance of noise monitoring. Applying the criteria for selecting a suitable sampling day was intended to increase the collection of noise measurements of relevant tasks. Aside from that, there was no additional control over the tasks and equipment monitored. As a result, there were disproportionate numbers of measurements among the tasks and equipment, with some having 30 or more measurements and other having less than five.

A limitation that may explain the large variability seen in the task and equipment noise exposures was the inability to account for distances from noise sources during monitoring. As sound energy radiates from a source, the intensity of the noise decreases by six decibels when the distance from the noise source is doubled (Berger et al., 2003). A large amount of information on the tasks and equipment was collected by directly observing the participants, but it was not feasible to collect information on the distances between the participants and the noise sources. Because the farmers and equipment in this work environment are mobile, it is likely any attempt to measure distance from noise sources would have been inaccurate. Furthermore, equipment differences (e.g., speed of moving parts, types of motors), work practices, number of additional noise sources, and the work area were not accounted for and could possibly explain the variability in the task and equipment noise exposures.

The greatest limitation of this study is that the results may not be generalizable to other farms and/or farmers. The farmers who participated in this study were predominantly male $(97 \%)$, which reflects the gender distribution of farmers in the study area (97\% and 93\% male) (USDA, 2007a, 2007b). However, the average age of the farmers who participated in this study was less (43 years) than that of farmers nationwide (55 years) (NASS, 2007). In addition, the average size of the participating farms was much larger (2357 acres) than that of farms nationwide (418 acres) (NASS, 2007). This is likely the result of the convenience sample, which resulted in a sample of mostly fulltime farmers from larger operations. Larger farms may be wealthier and have newer equipment with better noise control or have taken steps to integrate noise controls into 
their operation. Therefore, it is possible that the farm size and equipment age biased the noise measurements and gave the impression that the noise exposures for farmers are not as hazardous.

A major strength of this study was the collection of task and equipment data through direct observation by a field researcher, as opposed to interviewing the farmers at the end of the workday or having the farmers record their tasks in a diary. Misclassification of tasks with their corresponding one-minute noise measurements was likely reduced because clear start and stop times for the tasks were recorded. Several studies have shown that there can be differences in task information when self-reported using task diaries or by worker recall at the end of the day. One study found that users of task diaries underreported the changes in tasks, resulting in tasks of short duration not being recorded at all, as well as recorded start and stop times that did not correspond to the actual times when tasks were conducted (Unge et al., 2005). Another study, comparing the agreement of task diaries to direct observation of tasks in a musculoskeletal study, found that selfreported task diaries can cause misclassification of tasks and result in inaccurate taskbased exposure assessments (Van der Beek et al., 1994). A third study, specific to taskbased noise exposures, found moderate agreement between tasks reported using worker diaries and observations made by researchers, with kappa statistics between 0.51 and 0.67 (Reeb-Whitaker et al., 2004).

Another important strength of this study is the capacity to incorporate future noise measurements and task data into the task-based noise exposure database. The observational form can be used to collect additional data in a manner similar to the current study. This will increase the number of task-based noise measurements and improve the accuracy of future mean task and equipment noise exposures. Furthermore, because the database was designed to permit tasks to be determined a posteriori, the database can be shared with other researchers and allow tasks to be categorized to their desired level of specificity.

\section{Conclusions}

Several tasks with high mean noise exposures, such as operating grain vacuums and loading/unloading grain bins were identified. Overall, the noise exposures for the 23 tasks and 18 pieces of equipment ranged from 78.6 to $99.9 \mathrm{dBA}$, and most had standard deviations greater than three decibels. Because of the small sample sizes and high variability, statistically significant differences between most of the mean task and equipment noise exposures were not found. In addition, for nearly every task and piece of equipment, there were occurrences of noise measurements intense enough to cause hearing loss.

The large variability in the mean noise exposures indicates that using task and equipment noise exposures to target specific agricultural tasks for intervention strategies still has limitations. Focusing interventions on just a few tasks or equipment with the highest noise exposures would diminish farmers' overall noise exposure, but exposure to hazardous noise would likely still exist due to the variability in the noise exposures and the occurrence of high noise measurements for nearly every task and piece of equipment. Given this, controlling noise at the source (e.g., reducing the noise produced by equipment and tools) is the most effective approach to reducing noise exposures for farmers and farm workers in such a dynamic work environment. However, technological limitations and cost would make this impractical. 
The use of hearing protection is another possible control option. If tasks with consistently high or low mean noise exposures had been identified, efforts to promote the use of hearing protection among farmers and farm workers could be targeted to specific tasks or equipment with high exposures. However, the variability in the noise exposures examined in this study indicates that hearing protection use should not be ignored for any task, because high-intensity noise could still be present. Therefore, continuous use of hearing protection by farmers, when engaged in any agricultural task, is the only way to ensure protection from hazardous noise levels.

Although the variability in the mean noise exposures indicates that no agricultural task or piece of equipment should be overlooked as a potential source of hazardous noise, the database developed from this study still has important implications for future work. The data from the observational form can be used to examine how farm characteristics and work practices affect noise exposures. The data could also potentially be used to develop mathematical models that could estimate noise exposures for farmers and farm workers. A model that can accurately estimate noise exposures would allow health and safety professionals to determine noise exposures for workers in an industry that is largely unregulated and unlikely to pay for comprehensive noise monitoring.

\section{References}

Benke, G., M. Sim, L. Fritschi, and G. Aldred. 2000. Beyond the job exposure matrix (JEM): The task exposure matrix (TEM). Ann. Occup. Hygiene 44(6): 475-482.

Berger, E. H., L. H. Royster, D. P. Driscoll, J. D. Royster, and M. Layne, eds. 2003. The Noise Manual. 5th ed. Fairfax, Va.: American Industrial Hygiene Association.

Depczynski, J., R. C. Franklin, K. Challinor, W. Williams, and L. J. Fragar. 2005. Farm noise emissions during common agricultural activities. J. Agric. Safety and Health 11(3): 325-334.

Eduard, W., and B. Bakke. 1999. Experiences with task-based exposure assessment in studies of farmers and tunnel workers. Norsk Epidemiol. 9(1): 65-70.

Franklin, R. C., J. Depczynski, K. Challinor, W. Williams, and L. J. Fragar. 2006. Factors affecting farm noise during common agricultural activities. J. Agric. Safety and Health 12(2): 117-125.

Goldberg, M., S. M. Levin, J. T. Doucette, and G. Griffin. 1997. A task-based approach to assessing lead exposure among iron workers engaged in bridge rehabilitation. American J. Ind. Med. 31(3): 310-318.

Humann, M., W. Sanderson, G. Flamme, K. M. Kelly, G. Moore, A. Stromquist, and J. A. Merchant. 2011. Noise exposures of rural adolescents. J. Rural Health 27(1): 72-80.

Lander, L. I., S. N. Rudnick, and M. J. Perry. 2007. Assessing noise exposures in farm youths. J. Agromed. 12(2): 25-32.

McBride, D. I., H. M. Firth, and G. P. Herbison. 2003. Noise exposure and hearing loss in agriculture: A survey of farmers and farm workers in the southland region of New Zealand. J. Occup. Environ. Med. 45(12): 1281-1288.

Milz, S. A., J. R. Wilkins 3rd, A. L. Ames, and M. K. Witherspoon. 2008. Occupational noise exposures among three farm families in northwest Ohio. J. Agromed. 13(3): 165-174.

NASS. 2007. 2007 Census of Agriculture. Publication No. AC-07-A-51. Washington, D.C.: USDA National Agricultural Statistics Service.

NIOSH. 1998. Criteria for a recommended standard: Occupational noise exposure, revised criteria 1998. Publication No. 98-126. Cincinnati, Ohio: National Institute for Occupational Safety and Health.

Reames, G. J., S. G. Brumis, and M. Nicas. 2001. Task-specific lead exposure during residential lead hazard reduction projects. Appl. Occup. Environ. Hygiene 16(6): 671-678.

Reeb-Whitaker, C. K., N. S. Seixas, L. Sheppard, and R. Neitzel. 2004. Accuracy of task recall for epidemiological exposure assessment to construction noise. British Med. J. 61(2): 135-142. 
Susi, P., M. Goldberg, P. Barnes, and E. Stafford. 2000. The use of a task-based exposure assessment model (T-BEAM) for assessment of metal fume exposures during welding and thermal cutting. Appl. Occup. Environ. Hygiene 15(1): 26-38.

Unge, J., G. Hansson, K. Ohlsson, C. Nordander, A. Axmon, J. Winkel, and S. Skerfving. 2005. Validity of self-assessed reports of occurrence and duration of occupational tasks. Ergonomics 48(1): 12-24.

USDA. 2007a. Census of agriculture county profile: Wilkin County, Minnesota. Washington, D.C.: USDA National Agricultural Statistics Service. Available at: www.agcensus.usda.gov/Publications/ 2007/Online_Highlights/County_Profiles/Minnesota/cp27167.pdf. Accessed 10 July 2010.

USDA. 2007b. Census of agriculture county profile: Richland County, North Dakota. Washington, D.C.: USDA National Agricultural Statistics Service. Available at: www.agcensus.usda.gov/ Publications/2007/Online_Highlights/County_Profiles/North_Dakota/cp38077.pdf. Accessed 10 July 2010.

Van der Beek, A. J., I. T. J. Braam, M. Douwes, P. M. Bongers, M. H. W. Frings-Dresen, J. H. A. M. Verbeek, and S. Luyts. 1994. Validity of a diary estimating exposure to tasks, activities, and postures of the trunk. Intl. Arch. Occup. Environ. Health 66(3): 173-178.

Verma, D. K., W. K. Cheng, D. S. Shaw, M. L. Shaw, P. Verma, J. A. Julian, R. E. Dumschat, and S. J. Mulligan. 2004. A simultaneous job- and task-based exposure evaluation of petroleum tanker drivers to benzene and total hydrocarbons. J. Occup. Environ. Hygiene 1(11): 725-737.

Warren, N. D., H. Marquart, Y. Christopher, J. Laitinen, and J. J. Van Hemmen. 2006. Task-based dermal exposure models for regulatory risk assessment. Ann. Occup. Hygiene 50(5): 491-503. 